\title{
Evaluation of Food Color Consumption and Determining Color Type by Thin Layer Chromatography
}

\author{
${ }^{1}$ Fereshteh Farzianpour, ${ }^{2}$ Gholamreza Jahead Khaniki, \\ ${ }^{3}$ Masoud Younesian, ${ }^{4}$ Bahman Banaei Ghahferkhi, ${ }^{5}$ Mehraban Sadeghi and ${ }^{6}$ Shayan Hosseini \\ ${ }^{1}$ Department of Health Management and Economics, \\ 2,3,4,5 Department of Environmental Health Engineering, \\ School of Public Health, Tehran University of Medical Sciences, Tehran, Iran \\ ${ }^{6}$ Department of Electrical Energy Management, School of Electrical, Amirkabir University, Tehran, Iran
}

Received 2012-09-01, Revised 2012-09-20; Accepted 2013-04-12

\begin{abstract}
The aim of this research was to investigate the role of the social demographic parameters of the people in charge of the facilities producing pastry, poolak (a type of coin-shaped candy) and rock candy in the consumption of food colors and to determine color type by thin layer chromatography in Shahr-e-kord city in 2011. This research was an interventional-analytical study and its target population is the people in charge of the facilities producing pastry, poolak and rock candy in Shahr-e-kord city. Social demographic data of the participants were collected using checklists and 720 samples of pastry, poolak and rock candy weighing at least $250 \mathrm{gr}$ were randomly taken over a period of 10 months. With respect to color additives, the samples were analyzed by Thin Layer Chromatography (TLC) in four groups: natural colors permitted artificial colors, forbidden artificial colors and without colors. $48.47 \%$ contained food color and $6.52 \%$ contained forbidden artificial food color. Sunset Yellow was the color the most consumed among the colors used. Regarding the results obtained, there is a high rate of consumption of artificial colors $(41.22 \%)$, sunset Yellow being the most consumed. Therefore, it is of great importance to raise the awareness and change the attitude of the people in charge in these jobs as well as the consumers with regard to the side effects of artificial colors, which can be done through the mass media and NGOs.
\end{abstract}

Keywords: Thin Layer Chromatography, Rock Candy, Poolak, Pastry, Food Colors, Shahr-E-Kord

\section{INTRODUCTION}

Food additives are substances that are added to foods in trivial amounts during the steps of production, storage and packaging to improve the maintenance, durability, appearance, texture, taste, color, smell or the nutritional value of the food (FI, 2010). In 1978, the Committee on Food Additives and Contaminants categorized food colors into the two groups of approved and not requiring permission (Pourahmadi, 2006). According to the color origin, food colors are classified into three groups of natural colors, artificial colors and pigments or mineral colors (Barrows et al., 2003). The list of permitted artificial colors according to the Iranian national standards No. 740 is as follows: yellow colors (quinoline, Sunset Yellow), red colors (azorubine, ponceau 4R, Allura Red) and blue colors (indigotine, brilliant blue) (NIS, 2002; Potera, 2010). Colors that are added to foods do not improve the nutritional value or quality of foods and just add attraction, brightness, endurance and marketability to foods (FSA, 2012). The first synthetic color was developed by Perkin (1886) and

Corresponding Author: Fereshteh Farzianpour, Department of Health Management and Economics, School of Public Health, Tehran University of Medical Sciences, Tehran, Iran 
after that, color additives were gradually introduced in the USA and Europe. However, just in the same year, the restrictions of using synthetic color additives were introduced (Perkin, 1886). Food colors may have toxic effect on human body (EB, 2012). Furthermore, colors may be associated with various complications such as asthma, urticaria, abortion, hyperactivity of children, carcinogenicity, decreased IQ of children, anaphylactic reactions, idiosyncrasy, weakening of the immune system, decreased WBC and lymphocyte count and vitamin B6 deficiency (Hinton, 2000; Geoffrey and Felix, 1991). However, although food colors may improve appearance of the final product, it may uncover the hidden defects of another food. Therefore, natural colors in food industry should be applied with enough cautious and knowledge. This is why scientific communities have tried to characterize color substances more accurately and almost every year the information on the color substances is updated according to the results of scientific studies. Moreover, the list of permitted colors is revised every few years and the color substances, which have been shown to be potentially harmful for health, are eliminated from the list of permitted colors (Lin et al., 1992; Collins et al., 1999). Natural colors are healthier than synthetic chemical colors. Nevertheless, the producers prefer synthetic colors, owing to their lower prices, being more stable and having higher color intensity. Synthetic chemical colors are mostly used in production of nonalcoholic drinks, candies, gums and cover of some chocolates. It should be noted that in some amounts and under some conditions, natural colors may also have toxic effects for human. Therefore, without considering toxicological studies, one cannot definitely state the absolute safety of color substances (Klassen and Doull, 1996; IFIC, 2011). Since the colors are water soluble, their consumption rate is increasing. Artificial food colors are all water soluble and are considered as acidic colors (NIS, 2002). Ozsoy and Leeuwen (2010) carried out a study to remove color from fruit candy waste using activated carbon adsorption. They showed that the highest removal of water soluble colors occur at the $\mathrm{pH}$ value of 3.5 and at this $\mathrm{pH}$ value, maximum adsorption of red, yellow and blue colors were $4.4,11.7$ and $2 \mathrm{mg}$ per each gr of food substance tested, respectively. In future, simultaneous use of alternative adsorption and ozonation would be more frequently used in removal of colors (Ozsoy and Leeuwen, 2010). In another study, Mathur et al. (2005) demonstrated that exposure of animal models to semitoxic doses of sunset blue leads to changes in total lipid storage of the body. Since lipids have structural functions in biological membranes of the body, this would influence their metabolism and may cause hazardous hepatic injuries such as necrosis (Mathur et al., 2005). The studies have indicated that even topical administration of colors may end in harmful effects for human health. For instance, in a study, which was carried out by the Food and Drug Administration (FDA) in 1990, it was observed that the color Fast green \#3 (FD90Green), which is used in drugs and cosmetic products with external use, would cause thyroid cancer in male rats. Thus, the FDA disapproved the color and emphasized that using the color is associated with danger (Hinton, 2000). According to the Delany Clause, "no additive shall be deemed safe if it is found to induce cancer when ingested by man or animal." This law is applied for additive substances, colors and animal drugs. If additive substances, colors, or drugs taken by human or animals induce cancer, which is repeatable and the disease is not secondary to nutritional and hormonal factors or physiological imbalance, then it is compatible with the clause (IFIC, 2011). Therefore, public introduction of natural colors and emphasizing their advantages would meet the diversity of customers' tastes and also maintain community health. This would also encourage producers to use natural colors in their products. For instance, substitution of artificial red colors with anthocyanin of barberry in food industries would be very helpful, since anthocyanin have different properties such as anti-inflammatory effects, prevention of capillary fragility and decreasing vascular permeability (Farzianpour et al., 2012; Egan et al., 2007). Another example is saffron, which is a completely natural color having several medicinal properties, including the anticancer effects (Shamsa et al., 2009).

\section{MATERIALS AND METHODS}

This research is a cross-sectional interventionalanalytical study, carried out to evaluate the role of social demographic characteristics of people in charge of the facilities producing pastry, poolak and rock candy in using food colors in Shahr-e-kord city. The study was performed in 2011 and used Thin Layer Chromatography (TLC) to determine the type of colors. Over a period of 10 months, 720 samples of pastry, poolak and rock candy weighing at least 250 gr were randomly taken from the facilities producing pastry, poolak and rock candy in Shahr-e-kord city. The samples were analyzed 
for the type of color according to the guidelines provided by the Administration of Laboratories, as provided in the following (Soltandalal et al., 2007). The samples were analyzed by TLC method with respect to color additives in four groups; natural colors, permitted artificial colors, forbidden artificial colors and without colors. Approved samples were pastry, poolak and rock candy without colors or containing natural colors and the disapproved ones were those containing permitted and forbidden artificial colors. The materials and instruments used in the study were chloridric acid, sulfuric acid, ammonium, Hamilton syringe, capillarity tube (hematocrit tube), white wool, solvent tank, distilled water, hood, silica gel plates (Germany), Bain-Marie bath, Erlen mayer flasks, acetic acid and butanol as solvent.

\subsection{Steps of TLC}

\subsubsection{Color Separation}

Since food colors are water soluble, color separation was performed according to this characteristic.

Sample preparation (removal of lipids) To separate the food colors particularly from stained starchy materials, the starchy materials should firstly be separated and then the colors be separated. Therefore, for substances with high amounts of starch, 10-15 gr of the macerated sample was weighed, poured into an Erlen mayer flask and then mixed with $100 \mathrm{~mL}$ of $2 \%$ ammonium in alcohol $70^{\circ}$. After $24 \mathrm{~h}$, supernatant liquid was picked and the precipitate was removed. Then, the solution was poured into a becher and placed on a Bain Marie bath and brought to boil until $80 \%$ of its water evaporated. In the following, $100 \mathrm{~mL}$ distilled water and $1 \mathrm{~mL}$ acid were added and the separation step was continued using white wool.

\subsection{Purification and Separation of Water Soluble Food Colors}

2-5 $\mathrm{mL}$ of the water soluble food color was dissolved in $100 \mathrm{~mL}$ distilled water and then $1 \mathrm{~mL}$ concentrated chloridric acid or acetic acid was added to acidify the solution. Then, the solution was placed on boiling water steam and a piece of white wool was placed in the solution. The remaining of the insoluble materials was removed from the solution to only deal with the color solution. After $1 \mathrm{~h}$, under the acidic condition, the artificial colors were adsorbed by white wool and the solution became almost colorless (since sugar interferes with transfer of the colors to wool fibers, it should be noted that the higher the sugar content of food material is, the lower amount of sample should be taken). Then, the wool was thoroughly washed with cold water to separate the food materials. Next, the wool was placed in a becher and $50 \mathrm{~mL}$ distilled water and $1 \mathrm{~mL}$ concentrated ammonium were added to the becher and the becher was placed in a Bain Marie bath. After 30-60 min, the colors adsorbed by wool fibers were separated and entered the basic environment. At this point, the wool which was completely colorful or contained small amounts of color was discarded and the color solution was kept in the boiling Bain Marie bath until drying. After evaporation of the liquid in the becher, only the color and probably small amounts of the food material is dried in the bottom of the becher. It should be noted that when small amounts of the food remained in the bottom of the becher, which interferes with the TLC step, $50 \mathrm{~mL}$ water and $1 \mathrm{~mL}$ acid and a piece of wool were again added to the remaining to remove materials other than the colors.

4-Staining the chromatography paper: Chromatography was performed on silica gel plates. To this end, the silica gel was firstly activated by placing the plates in an incubator with the temperature of 90 $100^{\circ} \mathrm{C}$ for $8-10 \mathrm{~min}$ to remove its humidity and activate the silica gel. Then, the plate was taken out and allowed to be cooled. The prepared plates were then horizontally graded by pencil from one direction and distances of $3 \mathrm{~cm}$ were specified on this ruler with pencil. Then, small amount of the separated color solution was stained on the plate with short contacts, such that the diameter of each color stain does not exceed 2-3 $\mathrm{mm}$. Below each stain, the details were written down and drying of the stains were facilitated by a hair dryer. If the color density was low in a stain, the staining was repeated to obtain desirable color density. Along with the separated colors, standard colors were used for comparison and identification of the colors.

\subsection{Preparation of TLC Tank}

In the TLC performed on silica gel plate, the chromatography is ascending and the solvent is placed in the bottom of the tank. To this end, the tank was firstly washed thoroughly and then the solvents normal butanol, distilled water and acetic acid (with the ratio of 20:12:5) were poured in the tank and stirred. After preparation of the tank, the stained plate was placed inside the tank, put 
the cap on the tank and when the solvent front approaches almost $4 \mathrm{~cm}$ to the upper end of the plate, the plate was taken out of the tank and let dry completely under a hood.

6-Determination of color and measurement of $\mathrm{Rf}$ value: In this step, the Rf value (measure of the distance travelled by sample colors in relation to the distance travelled by standard colors) was measured. However, there are different tables on travelling of various colors on the plate in different solvents. It should be considered that environmental conditions such as temperature, atmosphere pressure, air flow and freshness of the eluents influence the distance travelled by the colors. Therefore, relying on the tables provided in books cannot be the basis of measurements. Finally, with regard to the distance travelled by the colors, the type and name of the colors were identified. The data were analyzed using SPSS version 16.

\section{RESULTS}

According to Table 1, the highest frequency of people in charge of the facilities was observed in the age group 31-40, while most of those in charge had high school education level and had the working history of 15 years. As shown in Table 2 and 3, most pastry, poolak and rock candy samples contained colors. Furthermore, as given in Table 4, sunset yellow was the most frequently consumed color among the permitted food color and indigo carmine was not used in the samples. According to Table 5 and 6 the highest frequency of the people in charge of the facilities was observed in the age group of 31-40, of a high school level of education and working history of 1-5 years. Moreover, most poolak and rock candy samples containing colors were related to people in charge of facilities with secondary school education level, age range of 31-40 and working history of 1-5 years.

Table 1. Distribution of frequency samples based on class, in groups of ages, Education and Work experience in Shahr-e-Kord 2011

\begin{tabular}{|c|c|c|c|c|c|c|c|c|c|c|c|}
\hline \multirow[b]{2}{*}{ Type of class } & \multicolumn{2}{|c|}{ The total sample } & \multirow[b]{2}{*}{ Age } & \multicolumn{2}{|c|}{ The total sample } & \multirow[b]{2}{*}{ Education } & \multicolumn{2}{|c|}{ The total sample } & \multirow{2}{*}{$\begin{array}{l}\text { Work experience } \\
\text { (years) }\end{array}$} & \multicolumn{2}{|c|}{ The total sample } \\
\hline & $\mathrm{N}$ & $(\%)$ & & $\mathrm{N}$ & $(\%)$ & & $\mathrm{N}$ & $(\%)$ & & $\mathrm{N}$ & $(\%)$ \\
\hline \multirow{3}{*}{ pastry } & 87 & 48.3 & $<21$ & 12 & 6.66 & Primary & 26 & 14.4 & $1-5$ & 58 & 32.2 \\
\hline & & & $21-30$ & 45 & 25.00 & Guidance & 63 & 35.0 & $6-10$ & 42 & 23.4 \\
\hline & & & $31-40$ & 63 & 35.00 & & & & $11-15$ & 29 & 16.1 \\
\hline Poolak and & 93 & 51.7 & $41-50$ & 38 & 21.11 & Secondary & 69 & 38.3 & $16-20$ & 11 & 6.1 \\
\hline \multirow{2}{*}{ Rock Candy } & & & $51-60$ & 9 & 5.00 & Academic & 22 & 12.3 & $>20$ & 40 & 22.2 \\
\hline & & & $>60$ & 13 & 7.23 & & & & & & \\
\hline Total & 180 & 100 & Total & 180 & 100.00 & Total & 180 & 100.0 & Total & 180 & 100.0 \\
\hline
\end{tabular}

Table 2. Status food Colors Consumable in samples of pastry, Poolak and Rock Candy in Shahr-e-Kord 2011

\begin{tabular}{|c|c|c|c|c|c|c|c|c|}
\hline \multirow[b]{2}{*}{ Title } & \multicolumn{4}{|l|}{ Pastry } & \multicolumn{4}{|c|}{ Poolak and Rock Candy } \\
\hline & $\begin{array}{l}\text { The number } \\
\text { of usable }\end{array}$ & $(\%)$ & $\begin{array}{l}\text { Total non- } \\
\text { consumption }\end{array}$ & $(\%)$ & $\begin{array}{l}\text { The number } \\
\text { of usabl }\end{array}$ & $(\%)$ & $\begin{array}{l}\text { Total non- } \\
\text { consumption }\end{array}$ & $(\%)$ \\
\hline & 0 & 0.00 & 68 & 39.0 & 0 & 0.0 & 51 & 29.3 \\
\hline Unauthorized artificial food colors & 0 & 0.00 & 20 & 11.5 & 0 & 0.0 & 11 & 6.3 \\
\hline Orthochromatic & 13 & 7.47 & 0 & 0.0 & 10 & 5.7 & 0 & 0.0 \\
\hline No color & 73 & 41.95 & 0 & 0.0 & 102 & 58.7 & 0 & 0.0 \\
\hline Total & 86 & 49.50 & 88 & 50.5 & 112 & 64.4 & 62 & 35.6 \\
\hline
\end{tabular}

Table 3. Status food Colors Consumable in samples of Poolak and Rock Candy in Shahr-e-Kord 2011

\begin{tabular}{|c|c|c|c|c|c|c|c|c|}
\hline \multirow[b]{2}{*}{ Title } & \multicolumn{4}{|l|}{ Poolak } & \multicolumn{4}{|l|}{ Rock Candy } \\
\hline & $\begin{array}{l}\text { The number } \\
\text { of usable }\end{array}$ & $(\%)$ & $\begin{array}{l}\text { Total non- } \\
\text { consumption }\end{array}$ & $(\%)$ & $\begin{array}{l}\text { The number } \\
\text { of usable }\end{array}$ & $(\%)$ & $\begin{array}{l}\text { Total non- } \\
\text { consumption }\end{array}$ & $(\%)$ \\
\hline Permitted synthetic food colors & 0 & 0.0 & 65 & 35.0 & 0 & 0.0 & 66 & 35.4 \\
\hline Unauthorized artificial food colors & 0 & 0.0 & 7 & 3.8 & 0 & 0.0 & 9 & 4.8 \\
\hline Orthochromatic & 17 & 9.2 & 0 & 0.0 & 12 & 6.5 & 0 & 0.0 \\
\hline No color & 97 & 52.0 & 0 & 0.0 & 99 & 53.3 & 0 & 0.0 \\
\hline Total & 114 & 61.2 & 72 & 38.8 & 111 & 59.8 & 75 & 40.2 \\
\hline
\end{tabular}


Fereshteh Farzianpour et al. / American Journal of Applied Sciences, 10 (2): 172-178, 2013

Table 4. Distribution diversity Permissible colors and unauthorized food in samples of pastry, Poolak and Rock Candy in Shahr-eKord 2011

\begin{tabular}{|c|c|c|c|c|}
\hline \multirow[b]{2}{*}{ Color } & \multicolumn{2}{|c|}{ Pastry } & \multicolumn{2}{|c|}{ Poolak and Rock Candy } \\
\hline & $\mathrm{N}$ & $(\%)$ & $\mathrm{N}$ & $(\%)$ \\
\hline Quinoline yellow & 46 & 30.6 & 47 & 32.0 \\
\hline Sun set yellow & 55 & 36.6 & 74 & 50.3 \\
\hline Tartrazine & 8 & 5.3 & 3 & 1.7 \\
\hline ponceau 4R & 2 & 1.3 & 2 & 1.3 \\
\hline Azorubine & 2 & 1.3 & 1 & 0.6 \\
\hline Allura Red & 2 & 1.3 & 2 & 1.3 \\
\hline brilliant blue & 4 & 2.6 & 2 & 1.3 \\
\hline Indigo carmine & 0 & 0.0 & 0 & 0.0 \\
\hline $\begin{array}{l}\text { Unauthorized } \\
\text { artificial colors }\end{array}$ & 31 & 20.6 & 16 & 10.9 \\
\hline
\end{tabular}

Table 5. Frequency distribution of the poolake and candy colors based on education level, age and work experience in the groups studied in Shahr-e-Kord 2011

\begin{tabular}{|c|c|c|c|c|c|c|c|c|c|c|c|c|c|c|}
\hline \multirow[b]{3}{*}{ Education level } & \multicolumn{4}{|c|}{ The total sample colors } & & \multicolumn{4}{|c|}{ The total sample colors } & \multirow{3}{*}{$\begin{array}{l}\text { Work } \\
\text { experience }\end{array}$} & \multicolumn{4}{|c|}{ The total sample colors } \\
\hline & \multicolumn{2}{|c|}{ Sweeter } & \multicolumn{2}{|c|}{ Cookie } & \multirow[b]{2}{*}{ Age } & \multicolumn{2}{|c|}{ Sweeter } & \multicolumn{2}{|c|}{ Cookie } & & \multicolumn{2}{|c|}{ Sweeter } & \multicolumn{2}{|c|}{ Cookie } \\
\hline & $\mathrm{N}$ & $(\%)$ & $\mathrm{N}$ & $(\%)$ & & $\mathrm{N}$ & $(\%)$ & $\mathrm{N}$ & $(\%)$ & & $\mathrm{N}$ & $(\%)$ & $\mathrm{N}$ & $(\%)$ \\
\hline \multirow[t]{2}{*}{ Primary } & 8 & 4.6 & 9 & 5.2 & $<21$ & 9 & 5.2 & 5 & 2.8 & $1-5$ & 32 & 18.4 & 21 & 12.0 \\
\hline & & & & & $21-30$ & 30 & 17.2 & 20 & 11.5 & $6-10$ & 24 & 13.8 & 17 & 9.8 \\
\hline Guidance & 35 & 20.1 & 27 & 15.5 & $31-40$ & 34 & 19.5 & 22 & 12.7 & $11-15$ & 15 & 8.6 & 9 & 5.2 \\
\hline \multirow[t]{2}{*}{ Secondary } & 43 & 24.7 & 25 & 14.3 & $41-50$ & 16 & 9.2 & 15 & 8.6 & & & & & \\
\hline & & & & & $51-60$ & 4 & 2.3 & 3 & 1.7 & $16-20$ & 7 & 4.0 & 7 & 4.0 \\
\hline Academic & 15 & 8.6 & 11 & 6.3 & $>60$ & 8 & 4.6 & 7 & 4.0 & $>20$ & 23 & 13.2 & 18 & 10.3 \\
\hline Total & 10 & 58.0 & 72 & 41.3 & Total & 101 & 58.0 & 27 & 41.3 & Total & 101 & 58.0 & 72 & 41.3 \\
\hline
\end{tabular}

Table 6. Distribution of sweets with color samples based on education level, age and work experience in the groups studied in Shahr-e-Kord

\begin{tabular}{|c|c|c|c|c|c|c|c|c|c|c|c|c|c|c|}
\hline \multirow{3}{*}{\multicolumn{2}{|c|}{ Education level N }} & \multicolumn{3}{|c|}{ The total sample colors } & \multirow[b]{3}{*}{ Age } & \multicolumn{4}{|c|}{ The total sample colors } & \multirow{3}{*}{$\begin{array}{l}\text { Work } \\
\text { experience }\end{array}$} & \multicolumn{4}{|c|}{ The total sample colors } \\
\hline & & Poolak & \multicolumn{2}{|c|}{ Rock Candy } & & \multicolumn{2}{|c|}{ Poolak Rock } & \multicolumn{2}{|c|}{ Candy } & & \multicolumn{2}{|c|}{ Poolak } & \multicolumn{2}{|c|}{ Rock Candy } \\
\hline & & $(\%)$ & $\mathrm{N}$ & $(\%)$ & & $\mathrm{N}$ & $(\%)$ & $\mathrm{N}$ & $(\%)$ & & $\mathrm{N}$ & $(\%)$ & $\mathrm{N}$ & $(\%)$ \\
\hline Guidance & 34 & 18.3 & 32 & 17.2 & $\begin{array}{l}21-50 \\
31-40\end{array}$ & 30 & 16.6 & $\begin{array}{l}1 / \\
40\end{array}$ & $\begin{array}{r}9.1 \\
21.5\end{array}$ & $\begin{array}{l}6-10 \\
11-15\end{array}$ & $\begin{array}{l}16 \\
16\end{array}$ & 8.6 & 21 & 11.3 \\
\hline Secondary & 22 & 11.8 & 28 & 15.0 & $41-50$ & 23 & 12.4 & 14 & 7.5 & & & & & \\
\hline \multirow[t]{2}{*}{ Academic } & 14 & 7.5 & 13 & 7.0 & $51-60$ & 5 & 2.7 & 5 & 2.7 & $16-20$ & 9 & 4.8 & 9 & 4.8 \\
\hline & & & & & $>60$ & 8 & 4.3 & 6 & 3.2 & $>20$ & 17 & 9.2 & 13 & 7.0 \\
\hline Total & 89 & 47.8 & 87 & 46.7 & Total & 89 & 47.8 & 87 & 46.7 & Total & 89 & 47.8 & 87 & 46.7 \\
\hline
\end{tabular}

\section{DISCUSSION}

According to the results obtained, less than half of the samples could not be used, because of containing artificial colors. We used the TLC for analysis of the samples, which has been shown to be cost-effective, with a good efficiency in identification of the color type. In Iran, several studies have been carried out on food colors. However, there is only one study on the food colors in pastries in south Tehran and so far no study has been performed on the type of colors used in poolak and rock candy. This is the first study in Iran on these samples (Soltandalal et al., 2007). For determination of artificial colors. Nevertheless, TLC is more applicable Kucharska and Grabka (2010) used chromatography methods to determine the artificial colors in foods and reported that TLC, spectrophotometry and High Performance Liquid Chromatography (HPLC) could be employed since it is simpler, has lower costs and required shorter time for determination of the quality of color mixtures (Kucharska and Grabka, 2010). As defined, food additive is any substance, which is 
intentionally added to food at specific amount, with definite methods and for special purposes. Cross-reaction may occur between food additives and the substances naturally contaminating food materials; for instance between salicylates and tartrazine (Pourahmadi, 2006). In this study, after analysis of chromatography paper by comparison of the stain travelling with that of the standard color sample and determination of the color type, it was demonstrated that $51.52 \%$ of the samples did not have any additive color, while 6.52 and $34.73 \%$ of the samples contained forbidden and permitted artificial food colors, respectively and $41.25 \%$ of the samples were not approved for consumption. It should be noted that the samples contained either permitted or forbidden artificial colors were not approved for consumption, since according to the guidelines of the Ministry of Health, using any type of artificial color in facilities such as confectionaries and those producing poolak and rock candy is forbidden. This law is set because these facilities do not have technical manager and the facilities do not have the production license and health code required for using artificial colors. These facilities are allowed to use natural colors and colors of plant origin (Soltandalal et al., 2007; Sobotka et al., 1996). Previous studies have shown that even natural colors may be associated with harmful and toxic effects for human body. Thus, absolute safety has not been confirmed for any substances, particularly colors (Soltandalal et al., 2007). Considering the high costs of extraction and low effectiveness, instability with changes in environmental conditions and $\mathrm{pH}$ and low color value of natural colors and the little knowledge of those in charge of production facilities about natural colors and lack of instruments to measure trace amounts of artificial colors, the producers use artificial colors. According to our findings, the most frequently used artificial colors in the facilities evaluated were sunset blue as a forbidden artificial color, followed by quinoline, tartrazine and brilliant blue. In some samples, a combination of sunset blue, tartrazine and quinoline was used. The highest amounts of artificial colors were used in pastry and then rock candy samples. Colors are responsible for various complications such as asthma, urticaria, abortion, hyperactivity of children, carcinogenicity, decreased IQ of children, anaphylactic reactions, idiosyncrasy, sleeping disorders, hypertension, weakening of the immune system, decreased WBC and lymphocyte count and vitamin B6 deficiency. They also influence mitochondrial respiration, hepatic and renal function and T3 and T4 production (Hinton, 2000; Geoffrey and Felix, 1991). Tartrazine is a commonly used artificial substance, with orange color. It is mainly used in drinks such as orange juice and a wide range of packed foods and pharmaceuticals. Some of its adverse effects include hyperactivity of children, urticaria and skin rashes. Further, intolerance to aspirin in some people is attributed to this substance; such that $0.15 \mathrm{mg}$ of the color leads to an acute asthma attack. The mechanism underlying sensitivity to tartrazine is unknown. However, it seems that IgE antibodies and the prostaglandin synthesis involve in the process. Canthaxanthin is a carotenoid pigment and contrary to beta-carotene, it does not transform into vitamin A and its deposition in retina would cause retinopathy (Pourahmadi, 2006; Soltandalal et al., 2007). Amaranth, which is a water-soluble red color, is used in prepared soups, cakes, desserts and jams and is associated with carcinogenicity in mice (Geoffrey and Felix, 1991; Sobotka et al., 1996; Paumgartten et al., 2002).

Macioszek and Kononowicz (2004) performed a study to evaluate in vivo genotoxicity of two commonly used food colors; Quinoline blue and brilliant black, on human lymphocytes. Using two accurate and complementary methods of micronucleus and Comet assays, the genotoxicity of these colors was confirmed (Macioszek and Kononowicz, 2004).

\section{CONCLUSION}

Considering what was mentioned above, it is of great importance to raise the awareness of people in charge of different facilities, especially those producing pastry, poolak and candy rock about the Iranian national standards, including the permitted food colors No. 740, GMP and adverse and toxic effects of forbidden colors. It should be noted that in certain amounts and under some conditions, natural colors have also toxic effects on human health. Furthermore, the study indicates the importance of further checking and evaluations of these facilities by environmental health investigators. Various activities via mass media for enhancement of the knowledge level of susceptible consumers, particularly children would be effective in this respect. For instance, since yellow colors resemble the color of saffron, they are the most widely used colors. Therefore, scientific introduction and public substitution of natural colors and emphasis on their advantages would play an important role in maintenance of community health. Furthermore, replacement of artificial colors with nanoemulsion-based water soluble food colors or second generation natural colors; namely cap colors, would be helpful. 


\section{ACKNOWLEDGEMENT}

The researchers wish to thank kind cooperation of Food and Drug Administration in performing the tests. Furthermore, kind support of research offices of Shahr-ekord University of Medical Sciences and Tehran University of Medical Sciences is highly appreciated.

\section{REFERENCES}

Barrows, J.N., A.L. Lipman and C.J. Bailey, 2003. Color Additives: FDA's Regulatory Process and Historical Perspectives. U.S. Food and Drug Administration.

Collins, T.F., R.L. Sprando, M.E. Shackelford, D.K. Hansen and J. Welsh, 1999. Food and drug administration proposed testing guidelines for reproduction studies. Revision Committee. FDA Guidelines for developmental toxicity and reproduction, food and drug administration. Regul. Toxicol. Pharmacol., 30: 29-38. PMID: 10464044

EB, 2012. Food additive. Encyclopedia Britannica.

Egan, M.B., M.M. Raats, S.M. Grubb, A. Eves and M.L. Lumbers et al., 2007. A review of food safety and food hygiene training studies in the commercial sector. Food Control, 18: 1180-1190. DOI: 10.1016/j.foodcont.2006.08.001

Farzianpour, F., J.G. Khaniki, F. Batebi and M. Yunesian, 2012. Compare the effects of two educational methods on the health principles knowledge of employees in food preparation. Am. J. Applied Sci., 9: 1678-1683 DOI: 10.3844/ajassp.2012.1678.1683

FI, 2010. Food ingredients and colors. Food Insight.

FSA, 2012. Current EU approved additives and their E Numbers. Food Standards Agency.

Geoffrey, B.A. and M.B. Felix, 1991. Canthaxanthin and the eye: A critical ocular toxicologic assessment. Cut Ocular Toxicol., 10: 115-155. DOI: 10.3109/15569529109057908

Hinton, D.M., 2000. US FDA "Redbook II" immunotoxicity testing guidelines and research in immunotoxicity evaluations of food chemicals and new food proteins. Toxicol. Pathol., 28: 467-478. PMID: 10862567

IFIC, 2011. International Food information council foundation. Food Survey.

Klassen, C.D. and J. Doull, 1996. Casarett and Doull's Toxicology: The Basic Science of Poisons. 5th Edn., McGraw-Hill, New York, ISBN-10: 0071054766, pp: 1111 .
Kucharska, M. and J. Grabka, 2010. A review of chromatographic methods for determination of synthetic food dyes. Talanta, 3: 1045-1051. DOI: 10.1016/j.talanta.2009.09.032

Lin, C.S., S.E. Shoaf and J.C. Griffiths, 1992. Pharmacokinetic data in the evaluation of the safety of food and color additives. Regul. Toxicol. Pharmacol., 15: 62-72. DOI: 10.1016/02732300(92)90084-M

Macioszek, V.K. and A.K. Kononowicz, 2004. The evaluation of the genotoxicity of two commonly used food colors: Quinoline Yellow (E 104) and Brilliant black BN (E 151). Cell Mol. Biol. Lett., 9: 107-22. PMID: 15048155

Mathur, N., V. Chaudhary, M. Mehta and S. Gupta, 2005. Sunset yellow induced changes in the lipid profile in male albino rate. Biochem. Cell Arch., 5: 197-200.

NIS, 2002. Permitted Artificial Colors Persian. 4th Edn., Food and Drug Administration, Tehran, pp: 147.

Ozsoy, H.D. and J.V. Leeuwen, 2010. Removal of color from fruit candy waste by activated carbon adsorption. J. Food Eng., 101: 106-112. DOI: 10.1016/j.jfoodeng.2010.06.018

Paumgartten, F.J., R.R. De-Carvalho, I.B. Araujo, F.M. Pinto and O.O. Borges et al., 2002. Evaluation of the developmental toxicity of annatto in the rat. Food Chem. Toxicol., 40: 1595-601. PMID: 12176086

Perkin, W.H., 1886. The origin of the coal-tar industry, and the contributions of hofmann and his pupils. J. Chem. Soc. (London).

Potera, C., 2010. Diet and nutrition: The artificial food dye blues. Environ. Health Perspect., 118: A428A428.

Pourahmadi, J., 2006. General Toxicology, Persian. 1st Edn., Samat, Tehran, pp: 1840.

Shamsa, A., H. Hosseinzadeh, M. Molaei, M.T. Shakeri and O. Rajabi, 2009. Evaluation of Crocus sativus L. (saffron) on male erectile dysfunction: A pilot Study. Phytomedicine, 168: 690-693. DOI: 10.1016/j.phymed.2009.03.008

Sobotka, T.J., K.B. Ekelman, W. Slikker, Jr., K. Raffaele and D.G. Hattan, 1996. Food and drug administration proposed guidelines for neurotoxicological testing of food chemicals. Neurotoxicology, 17: 825-836. PMID: 9086506

Soltandalal, M, H.R. Mohamadi, A. Dastbaz and S. Vahedi, 2007. Surveillance on artificial colors in confectionery products by chromatography in Teh, Persian. Gorgaran Univ. Med. Sci. J., 9: 73-78. 